\title{
El portal web CaCoCu: un canal de cultura contemporánea de las universidades públicas andaluzas
}

The website CaCoCu: a channel of contemporary culture of the Andalusian public universities

José L. Bernier (1), David Gómez-Domínguez (2) y Gerardo Fernández-Rodríguez (3)

$(1,3)$ Dpto. de Arquitectura y Tecnología de Computadores - Universidad de Granada, ETSI Informática y Telecomunicación, jbernier@atc.ugr.es. (2) Biblioteca Universitaria - Universidad de Granada, Hospital Real, Cuesta del Hospicio S/N - 18071 - Granada, dgomez@ugr.es. (3) gerfer@correo.ugr.es.

\section{Resumen}

La Asociación de Universidades Públicas Andaluzas (AUPA) ha presentado un portal que ofrece contenidos multimedia relacionados con los actos culturales organizados por dichas instituciones, con objeto de difundir este rico patrimonio cultural a través de Internet. Este portal, denominado "CaCoCu", permite el acceso a material audiovisual tal como grabaciones de video y audio, documentos de texto o galerías de imágenes que versa sobre temáticas muy variadas. En este artículo se describe la arquitectura del portal, tanto en el aspecto tecnológico como en el documental, así como las funcionalidades y servicios que se prestan a través del mismo.
\end{abstract}

Palabras clave: Portales web. Web 2.0. Patrimonio cultural. Universidades. Andalucía. Videodifusión.

\section{Introducción}

Desde hace tiempo, las instituciones privadas y públicas que cuentan con grandes archivos documentales han puesto en marcha diferentes procedimientos para digitalizar sus fondos. Las ventajas de esta tarea son evidentes, ya que las tecnologías actuales permiten la búsqueda eficiente y el acceso ubicuo a los contenidos, a la vez se evita su degradación por el paso del tiempo.

Hasta hace relativamente poco tiempo, este proceso de digitalización estaba enfocado fundamentalmente a documentos de texto, imágenes fotográficas y archivos de audio. Sin embargo, en los dos últimos años ha aparecido una fuerte demanda de contenidos de video (Anderson, 2006; Estalella, 2006; Marín Amatler, 2005), de forma que cada día aparecen nuevos portales que permiten la visualización de archivos de video (Youtube, Eyespot, ....), la difusión de música (iTunes, Vitaminic...), y la emisión de

\begin{abstract}
The Association of Public Andalusian Universities (AUPA) has displayed a portal that offers diverse multimedia contents related to the cultural events organized by these institutions, with object to spread this rich cultural heritage through Internet. The website, named "CaCoCu", allows users to access to audio-visual material as audio or video recordings, text documents and image galleries related to different thematic. This paper describes the architecture of the web portal, taking into account the technological and documentary aspects, as well as the functionalities and services that are provided.
\end{abstract}

Keywords: Web portals. Web 2.0. Cultural heritage. Andalusia. Universities. Video broadcasting.

radio o televisión a través de IP. En este sentido, distintas entidades poseedoras de fondos audiovisuales están convirtiendo en digitales sus videotecas. Tal es el caso de Radio y Televisión Española, que cuenta con el mayor archivo audiovisual de España (Fernández, 2006), tanto en volumen como en riqueza (Martín Muñoz y López Pavillard, 1998).

El presente trabajo presenta un portal web que permite acceder a diversos contenidos multimedia relacionados con las actividades culturales organizadas por las universidades públicas andaluzas. Dichas universidades (1) colaboran a través de AUPA (Asociación de Universidades Públicas de Andalucía) en un proyecto denominado Atalaya, que pretende difundir los eventos culturales organizados por dichas instituciones. Una de las líneas de actuación es el portal Ca$\mathrm{CoCu}$ (Canal de Cultura Contemporanea, www. cacocu.es) que se presenta a continuación. 
CaCoCu constituye una base de datos que permite acceder gratuitamente a diversos archivos multimedia producto de diferentes eventos culturales organizados en el ámbito universitario andaluz. El portal se ha diseñado para ser una fuente documental que albergue y describa dichos materiales. Además, se proporcionan también diversas herramientas que facilitan la búsqueda, clasificación y acceso a los recursos almacenados. Entre ellos, hay grabaciones audiovisuales de eventos tales como representaciones de teatro, conferencias, seminarios, etc., grabaciones sonoras de conciertos, corales, producciones de estudio, etc., y otros materiales gráficos o textuales como libros, guías de exposiciones, galerías de fotos, etc. De esta manera, este valioso y variado testimonio cultural se publica en la red para ser visualizado bajo demanda.

Los materiales publicados en $\mathrm{CaCoCu}$ suponen una importante fuente de recursos para distintas entidades educativas, contribuyéndose así al elearning en el contexto del nuevo Espacio Europeo de Enseñanza Superior (EEES). Entre sus materiales, $\mathrm{CaCoCu}$ cuenta con presencias literarias o entrevistas a personalidades del mundo de las letras de la categoría de Rafael Alberti, José Saramago o Elena Martín Vivaldi, materiales que hasta ahora no eran fácilmente accesibles a cualquier persona y algunos de los cuales se podrían incluso considerar inéditos. Igualmente ocurre con diversas conferencias de diversas personalidades del mundo de la Ciencia como Víctor Aldaya o Margarita Salas. Estos son sólo algunos ejemplos que ilustran el interés que pueden suponer estos materiales como apoyo a la educación, ya que pueden ser utilizados como material educativo en institutos de enseñanza secundaria, universidades, cursos de doctorado, cursos de idiomas o de filología española, etc.

Este trabajo se organiza de la siguiente manera: la sección 2 describe las características técnicas del portal. La usabilidad y los modos de acceso son descritos en las secciones 3 y 4, respectivamente. En la sección 5 se describe la gestión interna del portal. Para finalizar, la sección 6 recoge las conclusiones y enumera algunas de las tareas contempladas como trabajo futuro.

\section{Arquitectura del portal}

La arquitectura básica del portal se sustenta sobre XHTML+CSS (World Wide Web Consortium) como tecnología de diseño web, PHP5 (PHP) como lenguaje de programación y MySQL (MySQL) como motor de bases de datos. Se ha escogido Apache (The Apache soft- ware foundation) como servidor web y Windows Media Server (Windows Media Server) como servidor de stream; ambos servidores se han instalado sobre máquinas distintas.

El portal ha sido realizado a medida en su totalidad, diseñándose un gestor de contenidos para llevar a cabo la administración y mantenimiento a través de páginas web.

En relación con los usuarios y sus perfiles de acceso se ha considerado la siguiente jerarquía:

- Administrador de la aplicación: tiene acceso a todos los servicios y a su administración.

- Colaborador: puede añadir contenidos al portal, editar las fichas descriptivas, moderar los comentarios o los foros, etc.

- Usuarios registrados: pueden acceder a servicios exclusivos y personalizados.

- Usuarios no registrados: tienen acceso a los contenidos del portal, pero no tienen acceso a algunos servicios restringidos.

En el desarrollo del portal, surgieron diversas dificultades técnicas entre las que pueden destacarse dos: la primera, relacionada con la difusión de video y la segunda, relacionada con el tratamiento documental de la diversidad de materiales recibidos.

La difusión de video o audio a través de Internet exige la utilización de formatos de stream. El stream de video permite que el archivo pueda visualizarse conforme avanza la descarga, sin tener que esperar a descargarlo completamente. Existen distintas tecnologías de stream, pero hay que tener en cuenta que las grabaciones de video que se proporcionan a través de CaCoCu tienen, por lo general, una duración superior a 1 hora, por lo que cualquier formato de stream no es eficiente. Fue necesario analizar las diversas tecnologías para escoger un formato adecuado, tras lo cual se decidió adoptar el formato Windows Media Video (wmv) (Windows Media Server) que, además de soportar la difusión de videos de larga duración, presenta algunas características importantes para los objetivos del portal:

- Difusión bajo demanda y en directo.

- Difusión multicast.

- Bajo demanda: Se puede adelantar el punto de inicio del video.

- Multiple Bit Rate (MBR): En un único archivo se puede codificar el video a distintos bitrates. El servidor de stream negocia con el cliente el bitrate óptimo en función del ancho de banda 
disponible, adaptándolo dinámicamente en tiempo de difusión si es necesario.

Así pues, las grabaciones de video se han codificado a distintos bitrates para que, por un lado, no se limite la calidad y, por otro, no se restrinja el acceso a usuarios con conexiones a Internet deficitarias. El usuario tiene la posibilidad de elegir entre dos rangos de calidad: el primero (baja calidad) ofrece un bitrate que oscila entre 96 y $150 \mathrm{Kbps}$, mientras que el segundo (alta calidad) oscila dinámicamente entre 200 y 450 Kbps. En cualquiera de estos rangos se usa una resolución de $400 \times 300$ pixeles, consistiendo la principal diferencia en que a baja calidad se usa un framerate de $15 \mathrm{fps}$ mientras que en alta es de $25 \mathrm{fps}$. Por otra parte, la calidad de audio es también inferior al escoger baja calidad, ya que así se baja el bitrate total.

En relación a la filosofía Web 2.0 (O'Reilly) merecen destacarse las siguientes características del portal:

- Se han respetado los estándares de diseño y accesibilidad, de forma que $\mathrm{CaCoCu}$ se ha implementado usando XHTML+CSS por un lado, y respetando la normativa WAI (Lawton Henry, 2005), por otro.

- Se permite la sindicación de contenidos (RSS).

- El acceso a los materiales puede realizarse mediante un navegador basado en descriptores (nube de etiquetas).

- Se envían alertas a aquellos usuarios que lo deseen para avisarles de novedades de su interés.

- La jerarquía de usuarios contempla la posibilidad de colaboradores que añadan contenidos y editen las descripciones. Además se abre la posibilidad futura de que los usuarios registrados puedan aportar creaciones artísticas propias, enriqueciendo los contenidos del portal.

- El portal se ha diseñado para ofrecer soporte multilingüe tanto a nivel de menús como de contenidos.

\section{Usabilidad}

El portal ofrece cuatro tipos de contenidos distintos, pudiéndose distinguir según el soporte en el que fueron editados originalmente: grabaciones de video, grabaciones de audio, imágenes y documentos de texto.

Estos materiales se han organizado en colecciones o galerías que agrupan aquellos contenidos que están relacionados entre sí, pudiendo ser estos contenidos de distinta naturaleza. Esta organización facilita la localización de documentos que versan sobre temáticas concretas, de forma que pueden accederse conjunta o individualmente. Por ejemplo, hay ciclos de conferencias, festivales de teatro o colecciones de fotografías que se agrupan en sus correspondientes colecciones, donde cada conferencia, representación o imagen son elementos individuales dentro de la colección. Cada colección se describe globalmente $\mathrm{y}$, además, cada elemento individual tiene asociado una descripción detallada (ver figura 1). El aspecto general de las páginas que visualizan algún medio es similar al mostrado en la Figura 1. El contenido se muestra en un visor situado a la izquierda y a su derecha aparece la ficha que lo describe. Una pestaña situada a la izquierda del visor ofrece diversas opciones que difieren según el tipo de material visualizado: video, audio, galerías de imágenes y documentos de texto.

Otros elementos a destacar son los comentarios que publican los usuarios y que aparecen bajo el visor, así como la lista de otros elementos de la misma colección que se muestra bajo su ficha descriptiva.

\subsection{Reproducción de vídeo}

Gran parte del material accesible desde CaCo$\mathrm{Cu}$ son grabaciones de video de obras de teatro, conferencias, lecturas poéticas, entrevistas, etc. Tal y como muestra la Figura 1, los controles permiten iniciar, pausar o parar la reproducción, así como ir hacia delante o hacia atrás. La pestaña de opciones permite escoger si reproducir el video a alta o baja calidad, tal como se describió en la Sección 2.

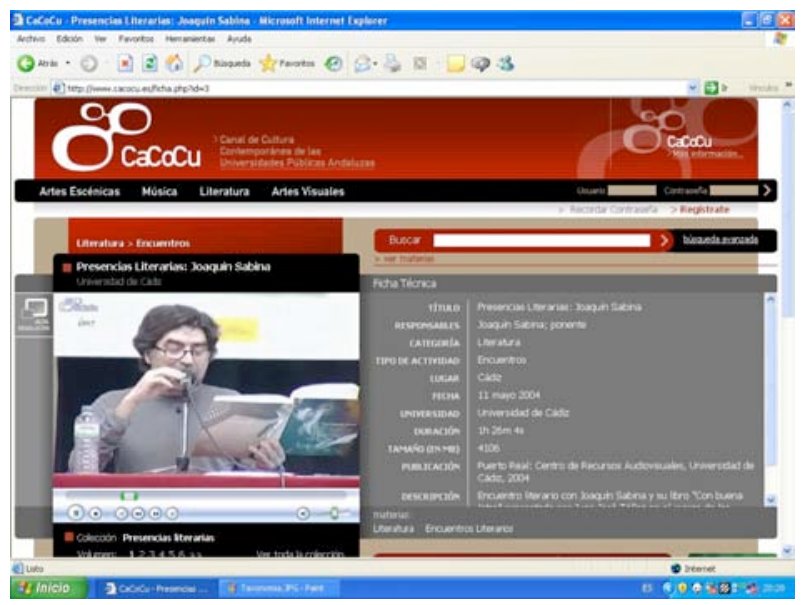

Figura 1. Aspecto general de una página que muestra algún contenido contemporánea de las universidades públicas andaluzas. // Ibersid. (2007) 151-156. ISSN 1888-0967. 
Para poder visualizar el vídeo en alta resolución, es requisito imprescindible ser usuario registrado del portal.

\subsection{Reproducción de audio}

Los archivos de audio se corresponden con grabaciones de conciertos, corales, producciones musicales editadas en estudio, etc. Tal y como muestra la Figura 2, el visualizador contiene la lista de temas desde donde se puede escoger la pista a reproducir. Los controles de audio permiten iniciar, pausar, o parar la reproducción. Como opciones, se puede mostrar en el visualizador la portada y contraportada del $\mathrm{CD}$ ampliadas, o descargar el libreto completo en formato pdf.

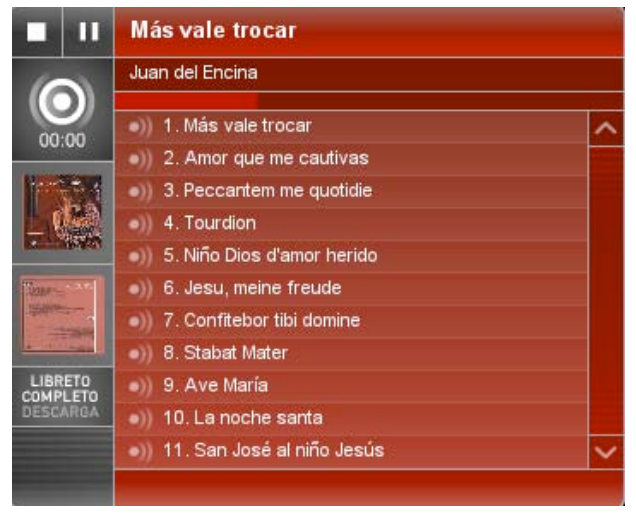

Figura 2. Reproducción de archivos de audio

\subsection{Galerías de imágenes}

Son colecciones de imágenes fijas relacionadas con exposiciones de pintura, escultura, fotografía, etc. Los controles permiten seleccionar la imagen que se muestra en el visor $y$, opcionalmente, puede activarse la visualización en alta resolución (Figura 3 ).

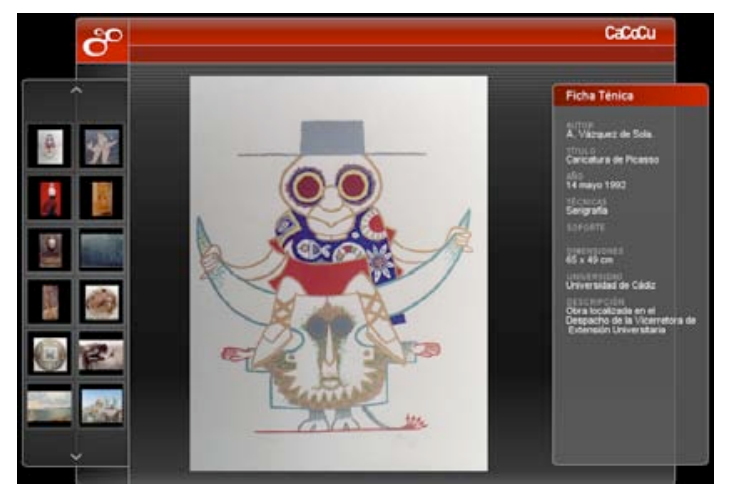

Figura 3. Reproducción de imágenes

\subsection{Documentos de texto}

Se trata de documentos tales como novelas, catálogos de exposiciones, folletos explicativos, etc. En este caso, las opciones permiten mostrar la portada y contraportada en el visor, así como descargar el contenido completo en formato pdf.

\subsection{Otros servicios}

Además de la difusión de los documentos descritos, el portal ofrece otros servicios de interés como son: buscadores de contenidos, comentar los contenidos, registro de usuarios, sindicación de contenidos, estadísticas de acceso, y administración de contenidos.

\section{Acceso a los contenidos}

Dada la gran variedad de contenidos ofrecidos y la diversidad de medios disponibles, se ha hecho especial hincapié en tratar de facilitar la localización de los materiales. De esta forma, el portal cuenta con cuatro puertas de entrada para que los usuarios puedan localizar sus contenidos. Así, dependiendo del manejo de la web y de los lenguajes de recuperación que posea el usuario, éste podrá acceder de una manera u otra. Estas puertas de entrada se encuentran resaltadas en la Figura 4.

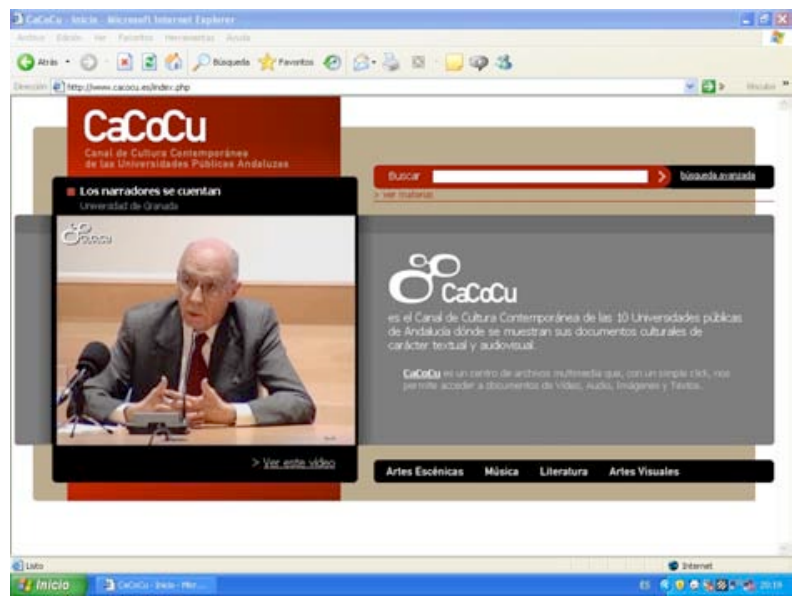

Figura 4. Puertas de entrada a CaCoCu.

\subsection{Taxonomía}

Una taxonomía previamente establecida permite acceder a los documentos en forma de directorio. Esta clasificación parte de cuatro categorías principales (Artes Escénicas, Música, Literatura y Artes Visuales) que se desglosan en diversas materias en un segundo nivel (Bernier, GómezDomínguez, Fernández-Rodríguez, Barchein y Pérez, 2007). 


\subsection{Nubes de etiquetas}

La opción "Ver materias" da acceso a dos nubes de etiquetas: la primera, de novedades, lista las materias de los documentos incorporados recientemente; y la segunda, de popularidad, lista las materias asignadas con mayor frecuencia a los documentos.

En cualquier caso, el peso o importancia de la materia se describe visualmente mediante el tamaño de letra usado para escribirla.

\subsection{Búsqueda simple}

Esta opción permite localizar aquellos documentos que contienen un término de búsqueda determinado en cualquiera de los campos que los describen.

\subsection{Búsqueda avanzada}

Esta opción permite establecer condiciones de búsqueda más complejas que en el caso anterior. Se ofrecen dos tipos de búsquedas avanzadas: mediante la combinación inclusiva 0 exclusiva de varias palabras clave y mediante la combinación de diferentes campos.

En cualquier tipo de búsqueda, el resultado se muestra en un formato similar al que se aprecia en la Figura 5.

Se observa que cada documento aparece acompañado de algunas imágenes fijas representativas del mismo, una descripción corta y la lista de materias que lo caracterizan. Además, se indica mediante un icono el tipo de material (video, audio, etc).

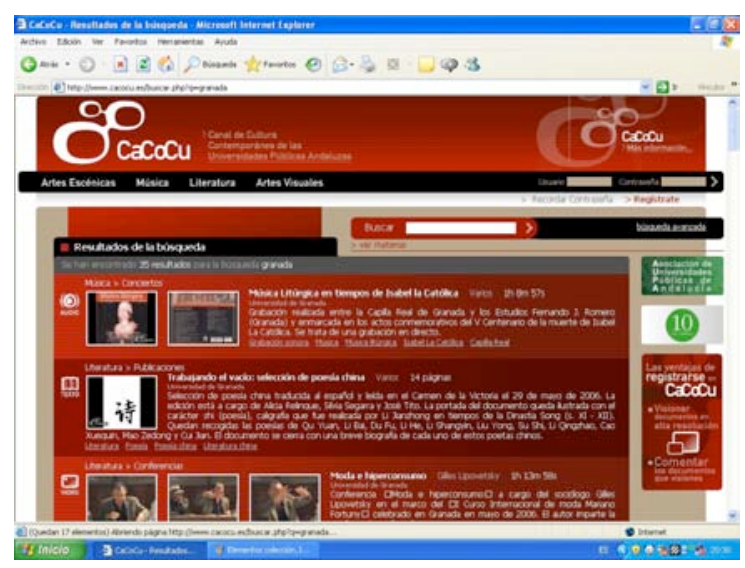

Figura 5. Resultados de una consulta.

\section{Gestión del portal}

La administración del portal se realiza a través de su propia interfaz. El sistema de administración (Figura 6) permite la gestión de: catalogo, usuarios registrados, comentarios y traducciones y el acceso al resumen de estadísticas de acceso.

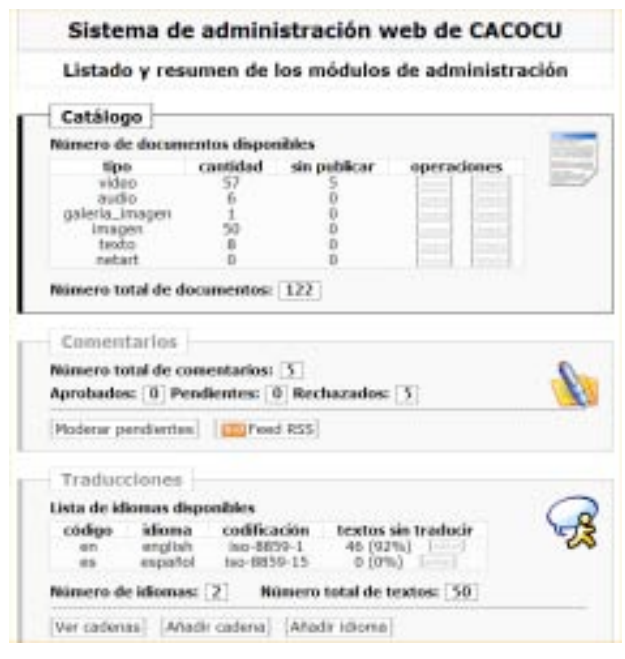

Figura 6. Menú principal de administración.

\subsection{Gestión del catálogo}

A través de esta herramienta se pueden añadir, editar o eliminar documentos. Como se observa en la Figura 6, una tabla resume el estado actual de los distintos tipos de contenidos; por ejemplo, se aprecia que se dispone de un total de 57 archivos de video, de los cuales hay 5 que aún no son accesibles para su consulta ya que falta completar algún apartado de su contenido.

\subsection{Gestión de usuarios}

Aunque el acceso al portal y a sus contenidos son gratuitos, se ha definido una política de registro de usuarios por dos motivos principales: a) recaudar información estadística sobre los perfiles y gustos de los visitantes, b) personalizar y restringir algunos servicios (edición de contenidos, alertas, visualizar video en alta calidad, añadir comentarios, etc).

\subsection{Gestión de comentarios}

$\mathrm{CaCoCu}$ está abierto a que los usuarios registrados puedan enriquecer los contenidos mediante sus comentarios. No obstante, dado el carácter institucional del portal, así como la seriedad de los documentos que se ofrecen y las fuentes de donde proceden, es necesario contar con una herramienta para la gestión de 
los comentarios, y que permita revisarlos e incluso eliminarlos si es preciso.

\subsection{Gestión de traducciones}

El portal se ha diseñado para dar soporte multilingüe, de forma que las fichas descriptivas del portal pueden ser ofrecidas en distintos idiomas, así como los menús de acceso a las distintas secciones.

\section{Conclusiones}

Se ha implementado un portal web que ofrece diversos contenidos multimedia relacionados con las actividades culturales organizadas por las universidades públicas de Andalucía: grabaciones de video y audio, galerías de imágenes y textos. Este portal se ha denominado "Canal de Cultura Contemporánea (CaCoCu)", y se encuentra accesible en http://www.cacocu.es. El portal cuenta ya con más de 120 documentos, de los cuales 57 se corresponden a grabaciones de video con una duración media superior a 1 hora. Este fondo se incrementa con las contribuciones de las diez universidades participantes que remiten nuevos materiales para ser convertidos a los formatos adecuados y publicados en el portal.

Los contenidos se corresponden con representaciones de obras de teatro, conferencias, reportajes y entrevistas a personajes ilustres del mundo de la cultura, exposiciones, conciertos, novelas, etc. Estos documentos suponen una gran fuente de recursos para la docencia y educación, ya que se pone a libre disposición y bajo demanda un rico patrimonio cultural que puede ser utilizado como material lectivo o de apoyo por distintas entidades educativas: institutos de enseñanza secundaria, universidades, doctorandos, etc. De hecho, aunque aún no se ha publicitado ni presentado oficialmente a los medios, ya hay diversas instituciones culturales que hacen referencia a los contenidos del portal como, por ejemplo, diversas instituciones de estudios marroquíes que enlazan el ciclo de conferencias sobre "Mujeres árabes hoy".

Como trabajo futuro, además de seguir añadiendo los nuevos materiales que generen las universidades, se pretenden abordar otras tareas:

- Difusión de video en directo.

- Ampliar la funcionalidad del portal: activación de alertas, implementación de unos foros de discusión, posibilidad de que los usuarios suban sus propias creaciones (módulo de Net.Art), administración de un blog para informar sobre nuevos materiales o herramientas, etc.
- Recuperar el patrimonio cultural más antiguo, convirtiéndolo en un formato digital y haciendo más accesible la memoria histórica de las universidades andaluzas.

- Traducción a otros idiomas.

- Conversión automática y on-line de video al formato wmv.

- Emisión de radio por IP.

$\mathrm{Ni}$ que decir tiene, que $\mathrm{CaCoCu}$, está en la línea de la filosofía del Open Access, del acceso abierto a los recursos informativos electrónicos.

\section{Notas}

(1) Las diez universidades que conforman AUPA son: Universidad de Almería, Universidad de Cádiz, Universidad de Córdoba, Universidad de Granada, Universidad de Huelva, Universidad Internacional de Andalucía, Universidad de Jaén, Universidad de Málaga, Universidad Pablo de Olavide, Universidad de Sevilla.

\section{Referencias}

Anderson, C. (2006). The Long Tail: Why the Future of Business Is Selling Less of More. // Hyperion.

Estalella, E. (2006). El video se cuela con fuerza en Internet. // Cinco Días.

Marín Amatller, A. (2005). Video digital en Internet. // Mosaic: tecnologías y comunicación multimedia. 41.

Fernández, Ángel (2006). Proyecto de Transformación y Digitalización de los Fondos Documentales de TVE. ¡Alarma!: Televisión Española guarda 200.000 horas de grabaciones en peligro de destrucción. http://www.con sultoras.org/frontend/plantillaAEC/noticia.php?id_noticia =5622\&PHPSESSID=964 (2007-07-05).

Martín Muñoz, J. y López Pavillard, J. (1998). RTVE: Reorganización de la documentación en un entorno multimedia. // Cuadernos de documentación multimedia.

World Wide Web Consortium. http://www.w3.org (2007-0705).

PHP: Hypertext Processor. http://www.php.net (2007-07-05).

MySQL AB: The world's most popular open source database. http://www.mysql.com (2007-07-05).

The Apache Software Foundation. http://www.apache .org (2007-07-05).

Windows Media Services 9 Series. http://www. microsoft.com/windows/windowsmedia/forpros/server/server.a spx (2007-07-05).

Lawton Henry, Shawn (2005). Introducción a la accesibilidad web. http://www.w3c.es/Traducciones/es/WAl/intro/ac cessibility (2007-07-05).

O'Reilly, T. What is Web 2.0: Design Patterns and Business Models for the Next Generation of Software. http://www.oreillynet.com/pub/a/oreilly/tim/news/2005/09/ 30/what-is-web-20.html (2007-07-05).

Bernier, JL., Gómez-Domínguez, D., FernándezRodríguez,G, Barcheín, M. y Pérez, G. (2007). CaCoCu: un portal web para la difusión de contenidos multimedia culturales de las universidades públicas andaluzas. // El profesional de la información. 16:3 (Mayo-Junio 2007) 216-224. 